Family Medicine and Community Health

\section{Practical recommendations for the prevention and management of COVID-19 in low-income and middle- income settings: adapting clinical experience from the field}

To cite: Fahme SA, Walsh KF, Rouzier V, et al. Practical recommendations for the prevention and management of COVID-19 in low-income and middle-income settings: adapting clinical experience from the field. Fam Med Com Health 2021:9:e000930. doi:10.1136/fmch-2021-000930

Received 13 January 2021 Revised 18 March 2021 Accepted 18 March 2021
Check for updates

(C) Author(s) (or their employer(s)) 2021. Re-use permitted under CC BY-NC. No commercial re-use. See rights and permissions. Published by BMJ.

For numbered affiliations see end of article.

Correspondence to Dr Sasha Abdallah Fahme; saf7007@med.cornell.edu

\section{INTRODUCTION}

Efforts to contain and respond to the novel COVID-19 in both high-income and lowincome countries remain extremely challenging. Resource-constrained countries face the additional obstacles of limited health infrastructure and inability to socially distance due to crowded and often multigenerational living conditions. As Western nations begin mass vaccination campaigns, many countries in the Global South may not receive the vaccine for months or years. Until this 'vaccination gap' is filled, we must prioritise community-based prevention measures, while continuing to share and learn from each other's clinical experiences, adapting management approaches to severely resource-limited settings in which vaccination may be delayed.

We are global health physicians who have been COVID-19 first responders in hospitals and clinics in both New York City and diverse low-income and middle-income countries (LMICs) across Africa, the Middle East and the Caribbean. We report our experiences in the field across these various settings with the goal to summarise our practices in the prevention and management of this disease, emphasising evidence-based interventions that can be realistically implemented in LMICs. All efforts should be contextualised to the individual setting, which is partially dependent on the capacity of each country's health systems.

\section{COVID-19 PREVENTION RECOMMENDATIONS}

Community-based prevention interventions are paramount to ensure a successful public health response. In New York City, government-mandated social distancing measures were delayed by nearly 2 weeks following the first confirmed case of COVID-19 on 3 March 2020, after which 5072 more were diagnosed. ${ }^{1}$ Emphasis on prevention should be placed with all the more urgency in resource-limited countries. LMICs have a rich history of robust prevention interventions, community partnerships and education to confront prior epidemics. ${ }^{2-4}$

\section{Community-based interventions}

The SARS-CoV-2 is spread primarily via respiratory droplets and through contact with contaminated surfaces. ${ }^{5}$ Preventative methods such as social distancing are impractical in densely populated areas in LMICs, particularly as strict lockdown measures depress fragile economies. However, some African governments have taken steps to reinforce social distancing by administering household surveys assessing the feasibility of safe and responsible self-isolation.

Increased handwashing is an effective behavioural change that can be promoted by public health organisations and healthcare workers (HCWs). To facilitate hand hygiene, our colleagues in Haiti erected 100-gallon water barrels with soap for handwashing at street corners in Port-au-Prince. Similar measures have been implemented across Tanzania, as depicted in figure 1. In Lebanon, where over $30 \%$ of the world's highest per capita refugee population reside in overcrowded slums, ${ }^{6}$ the United Nations High Commission for Refugees provided infection prevention training and distributed soap and hygienic kits to refugees. ${ }^{7}$ 


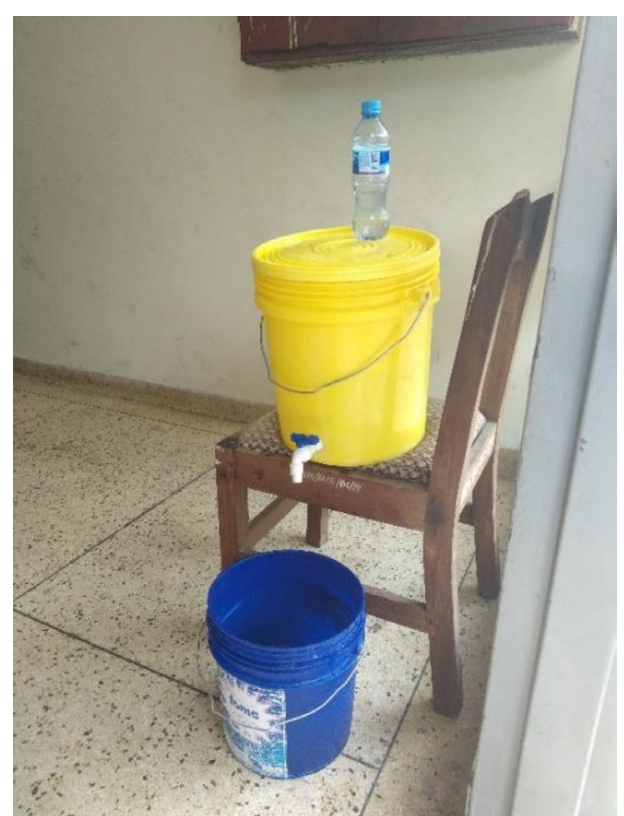

Figure 1 A homemade handwashing station assembled in a Tanzanian home.

Given the degree of asymptomatic shedding of SARS-CoV-2, ${ }^{8}$ universal mask wearing is a significant public health intervention to use in resource-limited settings. ${ }^{9}$ Though evidence for their use in healthcare settings is poor, ${ }^{10}$ cloth masks are feasible for community use. These can be produced at home at low cost. In the Idlib province of northwestern Syria, a women's organisation is producing and distributing cloth masks to internally displaced persons. ${ }^{11}$ Such grass-roots initiatives are essential for community engagement around infection prevention.

A major challenge to community prevention is rampant, fear-based misinformation. In many settings where we work, COVID-19 is extremely stigmatising, manifesting at times as violence. ${ }^{12}$ In New York, inequitable access to health information among racial and ethnic minorities may have contributed to health disparities related to COVID-19 infection rates and deaths. ${ }^{13}$ Unified, community-based public health messaging is needed to effectively address misinformation and strengthen community efforts around infection prevention.

Community health workers (CHWs), the backbone of the healthcare workforce and infrastructure in many LMICs, are fundamental to promoting these efforts. CHWled health awareness campaigns in refugee camps have demonstrated improved knowledge of disease prevention, service utilisation and protective behaviours. ${ }^{14}$ Leveraging their long-standing relationships and their roles as trusted health advocates within local communities, CHWs are the ideal candidates to circulate health information on COVID-19 symptoms, cough and hand hygiene, and when to seek medical care.

\section{Healthcare-based interventions}

Personal protective equipment (PPE) for HCWs is essential. There is general consensus that HCWs should cover all skin and mucus membranes that may be exposed to the virus, typically by using some form of gown, gloves, mask and protective eye wear. PPE should be composed of reusable items that can be easily decontaminated to maximise safe reuse among multiple patients.

New York City hospitals, including our own, experienced PPE shortages that required repurposing of non-traditional materials. Eye protection ranged from industrial lab goggles to three-dimensional printed face shields. Some hospitals used garbage bags as gowns. In March-April 2020, we reused the same N95 mask under a disposable surgical mask over several shifts, until it became visibly soiled or imperfectly sealed. Evidence since that time has shown that N95 mask reuse for greater than 2 days is associated with a $41 \%$ chance of failure compared with $9 \%$ risk when used for 2 days or less (OR 7.1; $95 \%$ CI 2.5 to $20 ; \mathrm{p}<0.0001) .{ }^{15}$ Additionally, newer studies have identified multiple effective methods of heat-based and chemical-based N95 mask decontamination and preservation. ${ }^{16}$ In particular, moist heat treatment emerged as among the most effective approaches to inactivating SARS-CoV-2 while maintaining the structural integrity of the mask. ${ }^{16}$ While some of these treatments may be impractical for wide application in LMICs, one study found that a similar, low-cost, moist heat-based decontamination method using widely available utensils could be both feasible and effective in resource-limited settings. ${ }^{17}$

LMIC governments should prepare for shortages by increasing local production of masks. For instance, the Tanzanian Ministry of Health commissioned local industries to produce masks and gowns for distribution in their health systems. PPE can also be conserved by the physical separation of confirmed SARS-CoV-2 cases, thus enabling HCWs to reuse PPE when consecutively examining patients. In our institution, plastic tarps were erected to separate patient areas when developing makeshift clinical spaces. Using extended tubing, we kept intravenous medication pumps outside of patient rooms, such that medications could be titrated without using PPE. In some settings, HCWs may conserve PPE by using free smartphone applications such as WhatsApp to remotely interview and triage patients.

Rigorous hand hygiene has also been suggested to limit nosocomial transmission among HCWs. ${ }^{18}$ In centres with limited or no running water, the WHO-recommended hand rub solutions which contain at least $30 \%$ alcohol have been shown to inactivate SARS-CoV-2 and may be an effective alternative. ${ }^{19}$

\section{COVID-19 TREATMENT RECOMMENDATIONS}

We describe management approaches to COVID-19 in resource-constrained settings. These suggestions are informed by our clinical experiences with COVID-19 
patients in New York City and LMICs, consultation of Society guidelines, and a rapid review of the available evidence, much of which is based on observational data. Apart from dexamethasone, which to date is the only therapeutic demonstrating a mortality benefit, the interventions discussed are primarily supportive. Table 1 summarises the suggested low-cost supportive interventions that may be realistically implemented in resourceconstrained settings.

\section{Non-pharmacological therapies \\ Oxygen}

Hypoxaemic respiratory failure is likely the most common cause of death in patients with COVID-19. ${ }^{20}$ Oxygen remains the mainstay of therapy, ${ }^{21}$ and in some settings may be the only available intervention. We and others anecdotally observed that many patients with COVID-19 may uniquely present with severe though asymptomatic hypoxia (oxygen saturation, $\mathrm{SpO}_{2}<85 \%$ ). ${ }^{21}$ While initially adopting an early intubation strategy for these patients, we soon realised that this approach was both unsustainable due to limited ventilator supplies, and potentially ineffective, as preserved lung compliance among some patients suggested an underlying mechanism of respiratory failure other than acute respiratory distress syndrome (ARDS). We adjusted our clinical practice to include the presence of respiratory distress when considering ICU admission for severely hypoxic patients.

In this paper, we focus on non-invasive oxygen therapy, as the majority of resource-poor countries will be without mechanical ventilation. For an excellent analysis of mechanical ventilation in COVID-19, we suggest Tobin. ${ }^{21}$ We similarly do not comment on non-invasive positive pressure ventilation, as this was rarely used in our setting, and may not provide additional benefits over supplemental oxygen in the treatment of COVID-19. ${ }^{21} 22$

Early initiation of oxygen supplementation anecdotally helped delay or prevent mechanical ventilation among patients with resting hypoxia $\left(\mathrm{SpO}_{2}<92 \%\right)$ hospitalised with COVID-19 at our institution. Using non-invasive methods, the fraction of inspired oxygen $\left(\mathrm{FiO}_{2}\right)$ can only be estimated and depends on the mode of delivery, with additional variability based on the quality of the device. For instance, a maximal rate of $6 \mathrm{~L}$ of oxygen per minute delivered by nasal cannula provides roughly $45 \% \mathrm{FiO}_{2}{ }^{23}$ The same amount of oxygen delivered through a "partial rebreather' face mask may provide closer to $60 \% \mathrm{FiO}_{2}$. A 'non-rebreather' mask may provide up to $95 \% \mathrm{FiO}_{2}$ while consuming up to $15 \mathrm{~L}$ of oxygen per minute. ${ }^{23}$ Oxygen monitoring in low-resource settings may be facilitated by portable pulse oximetry, a fairly inexpensive and reusable tool that may accurately identify patients at highest risk of decompensation. However, clinicians should bear in mind recent findings that occult hypoxaemia is less frequently detected by pulse oximetry in black than white patients. ${ }^{24}$

Piped oxygen availability may be limited in severely resource-constrained settings. In such settings, we recommend the decontamination and reuse of partial rebreather masks, which each cost approximately US\$2-US\$4, as the more efficient utilisation of oxygen represents an outstanding return on investments. We recommend adjusting supplemental oxygen to achieve a peripheral saturation of $92 \%-96 \%{ }^{25}$ or respiratory rate $<25$ in all hypoxic patients with COVID-19.

\section{Awake prone positioning}

Early prone positioning of awake, non-mechanically ventilated COVID-19 patients is a simple, no-cost intervention found in our practice to be highly effective at improving hypoxia. Observational data are inconsistent, with some studies demonstrating that awake proning may improve hypoxia and delay or prevent intubation, ${ }^{26}{ }^{27}$ and others finding no clinical benefit. ${ }^{28}$ Several clinical trials examining the role of awake prone positioning in this context are underway. ${ }^{29} 30$

Prone positioning homogenises aeration by decreasing intrapulmonary shunting and promoting recruitment of the dorsal lung segments. ${ }^{31}$ On this basis, we extended this practice to all awake, non-mechanically ventilated COVID-19 patients with moderate-to-severe hypoxia, with anecdotal improvement in oxygenation.

We recommend the early use of interval prone positioning on all hemodynamically stable, neurologically oriented COVID-19 patients with peripheral $\mathrm{SPO}_{2}$ below $92 \%$. Suggested contraindications to this practice include an inability to call for help, unstable fractures, pregnancy or presence of a chest tube.

\section{Pharmacological therapies Glucocorticoids}

There is high-quality evidence to support the use of glucocorticoids in the management of COVID-19. Corticosteroids may be valuable in the setting of hyperinflammation, ${ }^{32}$ though initially we were reluctant to use them to treat COVID-19 based on data from prior novel coronavirus outbreaks, which showed no benefit, and possible complications, with their use. ${ }^{33}$ We began to adapt our practices, however, first after a retrospective cohort study of 84 patients with COVID-19 and ARDS demonstrated a lower mortality risk among those who received methylprednisolone (HR 0.38; 95\% CI 0.20 to $0.72 ; \mathrm{p}=0.003$ ) ${ }^{34}$ Soon thereafter, an open-label randomised clinical trial of 2104 patients hospitalised with COVID-19 in the USA found a mortality benefit with dexamethasone use among those receiving non-invasive oxygenation (rate ratio 0.82; $95 \%$ CI 0.72 to $0.94 ; \mathrm{p}<0.001)$ and mechanical ventilation (rate ratio $0.64 ; 95 \% \mathrm{CI} 0.51$ to $0.81 ; \mathrm{p}<0.001) .{ }^{35}$ Glucocorticoids are inexpensive and frequently available in LMICs. We recommend their initiation in any patient with COVID-19 and hypoxia, defined as $\mathrm{SpO} 2 \leq 92 \%$, who does not otherwise have a contraindication to their use.

\section{Acetaminophen/paracetamol}

A total of $24 \%-94 \%$ of patients hospitalised with COVID-19 will experience a fever during their disease course. ${ }^{36}{ }^{37}$ Fevers increase metabolic oxygen consumption and thus worsen dyspnoea and hypoxia. Though 
Table 1 Suggested low-cost interventions with supporting evidence for the clinical management of COVID-19 pneumonia in resource-constrained settings

\begin{tabular}{|c|c|c|c|c|}
\hline Intervention & Evidence & Clinical use & Clinical settings & LMIC availability \\
\hline $\begin{array}{l}\text { Non-invasive } \\
\text { supplemental } \\
\text { oxygen (via NC or } \\
\text { NRB mask) guided } \\
\text { by pulse-oximetry }\end{array}$ & $\begin{array}{l}\text { Mainstay of therapy }{ }^{21} \\
\text { and recommended for } \\
\text { use in COVID-19 based } \\
\text { on expert consensus. }{ }^{22} \\
{ }^{25} \text { Anecdotally beneficial } \\
\text { in COVID-19 with } \\
\text { improvement in hypoxia } \\
\text { and work of breathing. }\end{array}$ & $\begin{array}{l}\text { All patients with suspected } \\
\text { or confirmed COVID-19 with } \\
\text { respiratory distress, } \mathrm{RR}>20 \text {, } \\
\text { or resting } \mathrm{SpO}_{2}<92 \% \text {. }\end{array}$ & Hospital & $\begin{array}{l}\text { Variable; pulse oximeter } \\
\text { frequently available; piped } \\
\text { oxygen may be limited } \\
\text { in severely resource- } \\
\text { constrained settings. }\end{array}$ \\
\hline
\end{tabular}

Awake prone positioning

\section{Inconsistent} observational data; Some studies suggest improvement in hypoxia among patients with severe respiratory failure and COVID-19, 2627 while others found no benefit. Anecdotally shown to be effective in improving hypoxia in COVID-19 patients who are oriented.

\begin{tabular}{|c|c|}
\hline $\begin{array}{l}\text { Standing } \\
\text { acetaminophen or } \\
\text { paracetamol }\end{array}$ & $\begin{array}{l}\text { Improves fevers and } \\
\text { respiratory distress } \\
\text { by reducing oxygen } \\
\text { consumption and } \\
\text { recommended for use in } \\
\text { COVID-19. }{ }^{22} \text { Anecdotally } \\
\text { effective in treating } \\
\text { myalgias and improving } \\
\text { work of breathing in } \\
\text { COVID-19 patients. }\end{array}$ \\
\hline Glucocorticoids & $\begin{array}{l}\text { Mortality benefit in } \\
\text { in hypoxic patients } \\
\text { hospitalised with } \\
\text { COVID-19. }{ }^{34} 35\end{array}$ \\
\hline Heparin or LMWH & $\begin{array}{l}\text { Improvement in } 28- \\
\text { day mortality among } \\
\text { select patients } \\
\text { with COVID-19.47 } \\
\text { Anecdotal observations } \\
\text { of high rates of } \\
\text { hemodynamically } \\
\text { significant } \\
\text { thromboembolic disease } \\
\text { in COVID-19 requiring } \\
\text { LMWH use. }\end{array}$ \\
\hline Low-dose aspirin & $\begin{array}{l}\text { Observational data } \\
\text { demonstrated aspirin } \\
\text { independently } \\
\text { associated with lower } \\
\text { risk of mechanical } \\
\text { ventilation, ICU } \\
\text { admission, and in- } \\
\text { hospital mortality among } \\
\text { hospitalised patients } \\
\text { with COVID-19.51 }\end{array}$ \\
\hline
\end{tabular}

All patients with suspected or Hospital; Clinic; Unlimited. confirmed COVID-19 with RR Home. $>20$ or resting $\mathrm{SpO}_{2}<92 \%$
All patients with suspected Hospital; Clinic; Widely available. or confirmed COVID-19 Home. with respiratory distress, $\mathrm{RR}$ $>20$, or resting $\mathrm{SpO}_{2}<92 \%$ irrespective of fever curve.

All patients with suspected or confirmed COVID-19 pneumonia and resting $\mathrm{SpO}_{2}$ $<92 \%$

Patients with suspected or confirmed COVID-19 with symptom duration $>7$ days, minimal bleeding risk, and one of the following: persistent temperature $>39.4^{\circ} \mathrm{C}$, respiratory failure, shock, kidney failure or clinically evident thromboembolic disease.

Patients with suspected or confirmed COVID-19 with symptom duration $>7$ days, minimal bleeding risk, Hospital/ICU; Clinic; Frequently available. Home.

Hospital/ICU. Variable drug availability; may be limited in more resource-constrained areas. Further limitations in laboratory testing limit safe administration in many LMICs.

\section{Hospital/ Widely available.}

ICU in which anticoagulation is not available. and one of the following: persistent temperature $>39.4^{\circ} \mathrm{C}$, respiratory failure, shock, kidney failure or clinically evident thromboembolic disease. 
acetaminophen has not been studied in COVID-19, it is nonetheless recommended for use in this context. ${ }^{22}$ Our experience with scheduled acetaminophen irrespective of fever curve has shown not only a reduction in fever occurrence but also improvement in work of breathing without significant hepatic toxicity. This drug is inexpensive and widely available globally. Notably, while non-steroidal anti-inflammatory drugs (NSAIDs) may be an alternative for patients with contraindications to paracetamol, these drugs have been anecdotally linked to poor outcomes in this setting. ${ }^{38}$ We have generally limited NSAID use in our practice, primarily due to a high prevalence of kidney injury. ${ }^{37}$

\section{Chloroquine and hydroxychloroquine}

Chloroquine and hydroxychloroquine have shown in vitro activity against SARS-CoV-2, prompting their use in patients early in the COVID-19 pandemic. ${ }^{39} 40$ However, data on in vivo activity indicated lack of effectiveness. ${ }^{41} 42$ The initially promising study of hydroxychloroquine in conjunction with azithromycin has since been retracted due to concerns over its methodology. ${ }^{43} \mathrm{~A}$ small randomised trial from China showed hydroxychloroquine had no effect on viral clearance compared with standard of care. ${ }^{41}$ A retrospective study of 368 patients with COVID-19 in the USA found an association of increased overall mortality with hydroxychloroquine use (HR 2.61; 95\% CI 1.1 to 6.17 ; $\mathrm{p}=0.03$ ). ${ }^{44}$ Most recently, a multicentre, blinded, placebo-controlled randomised clinical trial of 479 hospitalised adults in the USA with COVID-19 respiratory disease showed no clinical benefit at 14 days to support hydroxychloroquine use. ${ }^{45}$ Based on the current evidence, we do not recommend the use of these medications.

\section{Anticoagulation}

Haemostatic derangement appears to be a key component of severe COVID-19 illness. An observational study of 3334 patients hospitalised with COVID-19 across four New York City hospitals found that $16 \%$ of all patients and $29 \%$ of ICU patients experienced a thrombotic event, which included deep vein thrombosis $(3.9 \%)$, pulmonary embolism $(3.2 \%)$, myocardial infarction $(8.9 \%)$ and ischaemic stroke $(1.6 \%)$, during their hospitalisation. ${ }^{46}$ Further, thrombosis was independently associated with critical illness, elevated d-dimer levels $(\mathrm{p}<0.001)$, and allcause mortality (HR 1.82; 95\% CI 1.54 to 2.15 ; $\mathrm{p}<0.001$ ) ${ }^{46}$

Empiric anticoagulation may be useful in select patients. A retrospective analysis of 449 patients with COVID-19 showed that, among patients with elevated inflammatory markers, prophylactic heparin use conferred a lower 28-day mortality rate $(32.2 \%$ vs $52.4 \%$; $=0.017) .{ }^{47}$ Similarly, our hospital and others in New York City developed their own anticoagulation guidelines.

Prophylactic anticoagulation in this setting is recommended too by Society guidelines, often guided by inflammatory biomarkers, which may be useful for prognostication. ${ }^{46} 48$ In settings with limited laboratory capacity, however, the decision of whether to initiate anticoagulation may be determined by clinical severity including the presence of severe hypoxia $\left(\mathrm{SpO}_{2} \leq 90 \%\right)$, persistent high fever $\left(>39.4^{\circ} \mathrm{C}\right)$ despite standing paracetamol use, abdominal organomegaly and/or shock.

\section{Aspirin}

Unfractionated and low-molecular-weight- heparin may not be available in many resource-limited settings. If anticoagulation is not possible, it may be reasonable to trial low dose $(81 \mathrm{mg})$ aspirin. The inexpensive, widely available drug has been shown to inhibit pulmonary neutrophilia in the setting of lipopolysaccharide-induced ARDS, ${ }^{49}$ and was suggested to be a safe and effective alternative to anticoagulation in preventing postoperative venous thromboembolism in a cohort of postoperative patients. ${ }^{50}$ More recently, a multicentre retrospective study of 412 adults with COVID-19 hospitalised in the USA found that aspirin use was independently associated with a lower risk of mechanical ventilation (HR 0.56 ; $95 \%$ CI 0.37 to 0.85 ; $\mathrm{p}=0.007$ ), ICU admission (HR 0.57 ; $95 \%$ CI 0.38 to 0.85 ; $\mathrm{p}=0.005$ ) and in-hospital mortality (HR $0.53 ; 95 \%$ CI 0.31 to $0.90 ; \mathrm{p}=0.02$ ), though no differences were observed in thrombosis. ${ }^{51}$ Concomitant aspirin and anticoagulation use in patients with venous thromboembolism is associated with an increased risk of clinically significant bleeding (HR 1.70, 95\% CI 1.38 to 2.11) and has not been studied in the setting of COVID-19. ${ }^{52}$ We, therefore, only recommend aspirin use in patients with COVID-19 respiratory illness in whom anticoagulation is not feasible and who do not have any contraindications.

\section{Antiviral therapies}

Remdesivir was shown in a double-blind, randomised placebo-controlled trial of 1062 adults hospitalised with COVID-19 in the USA to be superior to placebo on the primary outcome of time to recovery (rate ratio 1.29; 95\% CI 1.12 to 1.49 ; $\mathrm{p}<0.001$ ), but did not confer a statistically significant survival benefit. ${ }^{53}$ Triple therapy with interferon beta-1B, lopinavir-ritonavir and ribavirin also showed effectiveness in reducing duration of symptoms and hospitalisation among a randomised phase 2 trial of 144 participants. ${ }^{54}$ Despite this promising data, these drugs are not universally available, with their use still confined to clinical trials. An increase in production and widespread dissemination of these medications is needed prior to their routine use in both high-resource and lowresource settings.

\section{Monoclonal antibodies and convalescent plasma}

The US Food and Drug Administration has recently granted emergency use authorisation for monoclonal antibody treatments in high-risk outpatients-but not those hospitalised-with COVID-19 including immunosuppressed persons and those with certain comorbidities, after preliminary data from placebo-controlled trials demonstrated a reduction in viral load and potentially decreased risk of hospitalisation. ${ }^{556}$ In addition to their 
expense, these medications are oftentimes impractical for use given their high-risk side effect profile, which has been cited as a primary factor in their underutilisation in even high-resource settings. ${ }^{57}$ Convalescent plasma may be more readily available in LMICs, though a recent multicentre, double-blinded, placebo-controlled randomised trial in Argentina found no mortality benefit from convalescent plasma among patients hospitalised with severe COVID-19 pneumonia. $^{58}$ Similarly, a randomised controlled trial conducted across 39 hospitals in India found that convalescent plasma use did not confer a mortality benefit nor reduction in severe disease among patients hospitalised with moderate COVID-19 illness. ${ }^{59}$ Additionally, case studies suggest that convalescent plasma use, particularly in immunosuppressed individuals with prolonged viral replication, may be associated with lower susceptibility to neutralising antibodies. ${ }^{60}$ At this time, we do not recommend convalescent plasma use in patients with moderate to severe COVID-19 illness, given its unclear benefit and potentially harmful public health implications.

\section{CONCLUSION}

The COVID-19 pandemic presents unique challenges to healthcare providers worldwide, and particularly those working in resource-limited settings. As harder hit wealthy nations begin vaccination campaigns, severe global inequities in vaccine distribution are feared to worsen the pandemic in low-income countries, where nine out of 10 individuals will not have access to any vaccine in the coming year. ${ }^{61}$ Aside from ubiquitous vaccination, there is no solution to overcome this pandemic, as evidenced by the diversity of management approaches adopted by institutions even just in New York City. Until vaccines are universally available, emphasis on prevention with community-based interventions aimed at reducing stigma and increasing awareness to reduce transmission is essential. This pandemic knows no geopolitical national boundaries, and we must learn from each other's experiences and mistakes to prepare the next epicentre's response.

\footnotetext{
Author affiliations

${ }^{1}$ Center for Global Health Research, Cornell University Joan and Sanford I Weill Medical College, New York, New York, USA

${ }^{2}$ Department of Health Promotion and Community Health, Faculty of Health

Sciences, American University of Beirut, Beirut, Lebanon

${ }^{3}$ GHESKIO, Port-au-Prince, Ouest, Haiti

${ }^{4}$ Catholic University of Health and Allied Sciences, Mwanza, Mwanza, Tanzania ${ }^{5}$ Department of Epidemiology and Population Health, Faculty of Health Sciences, American University of Beirut, Beirut, Lebanon
}

\section{Twitter Sasha Abdallah Fahme @SashaFahme}

Acknowledgements We thank Dr. Daniel Fitzgerald, Director of the Weill Cornell Center for Global Health, for his thoughtful review and support of this manuscript. We are grateful to Dr. Arthur Evans, Section Chief of Hospital Medicine, Division of General Internal Medicine, Weill Cornell Medicine, for his visionary leadership during this unprecedented pandemic. We are thankful to all our healthcare colleagues working tirelessly to provide patient care in this pandemic.

Contributors SAF conceived of the review, conducted the literature search, and wrote the manuscript. KW contributed to the literature review, writing, reviewing and editing of the manuscript. VR, PC, HJ, JRK, FMF, JSM and JAD were involved in the reviewing, writing and editing of the paper. MM contributed to the writing and supervised the literature search, writing and review of the manuscript. All authors reviewed the final manuscript and approved submission.

Funding This work was not supported by any funding sources.

Competing interests None declared.

Patient consent for publication Not required.

Provenance and peer review Not commissioned; externally peer reviewed.

Open access This is an open access article distributed in accordance with the Creative Commons Attribution Non Commercial (CC BY-NC 4.0) license, which permits others to distribute, remix, adapt, build upon this work non-commercially, and license their derivative works on different terms, provided the original work is properly cited, appropriate credit is given, any changes made indicated, and the use is non-commercial. See: http://creativecommons.org/licenses/by-nc/4.0/.

ORCID iDs

Sasha Abdallah Fahme http://orcid.org/0000-0003-0265-2582

Kathleen F Walsh http://orcid.org/0000-0002-9001-3918

Puja Chebrolu http://orcid.org/0000-0002-5422-2966

\section{REFERENCES}

1 NYC DOH. COVID-19: data. Available: https://www1.nyc.gov/site/ doh/covid/covid-19-data.page [Accessed 03 May 2020].

2 Chowdhury AM, Chowdhury S, Islam MN, et al. Control of tuberculosis by community health workers in Bangladesh. Lancet 1997;350:169-72.

3 Mwai GW, Mburu G, Torpey K, et al. Role and outcomes of community health workers in HIV care in sub-Saharan Africa: a systematic review. J Int AIDS Soc 2013;16:18586.

4 Miller NP, Milsom P, Johnson G, et al. Community health workers during the Ebola outbreak in guinea, Liberia, and Sierra Leone. $J$ Glob Health 2018;8:020601.

5 Omer SB, Malani P, Del Rio C. The COVID-19 pandemic in the US: a clinical update. JAMA 2020;323:1767-8.

6 UNHCR. Lebanon crisis response plan, 2019. Available: https:// data2.unhcr.org/en/documents/download/68651

7 United Nations High Commissioner for Refugees. Response to Coronavirus - COVID-19. Available: https://www.unhcr.org/lb/corona [Accessed 24 Apr 2020].

8 Gudbjartsson DF, Helgason A, Jonsson H, et al. Spread of SARSCoV-2 in the Icelandic population. N Engl J Med 2020;382:2302-15.

9 Leung NHL, Chu DKW, Shiu EYC, et al. Respiratory virus shedding in exhaled breath and efficacy of face masks. Nat Med 2020;26:676-80.

10 Maclntyre CR, Seale H, Dung TC, et al. A cluster randomised trial of cloth masks compared with medical masks in healthcare workers. BMJ Open 2015;5:e006577.

11 Dadouch S. As men wage bloody battle for Syrian Province, women sew face masks to fight the next threat. Washington Post, 2020.

12 Alstedter A, Shrivastava B, Pandya D. Doctors come under attack in India as coronavirus stigma grows. Bloomberg News, 2020.

13 Centers for Disease Control and Prevention. COVID-19 in racial and ethnic minority groups. Available: https://www.cdc.gov/coronavirus/ 2019-ncov/need-extra-precautions/racial-ethnic-minorities.html [Accessed 28 Apr 2020].

14 Ehiri JE, Gunn JKL, Center KE, et al. Training and deployment of lay refugee/internally displaced persons to provide basic health services in camps: a systematic review. Glob Health Action 2014;7:23902.

15 Check R. Failure rates during reuse of disposable N95 masks in clinical practice in the emergency department," presented at the American College of Emergency Physicians Research Forum, 2020. Available: https://els-jbs-prod-cdn.jbs.elsevierhealth.com/pb/assets/ raw/Health\%20Advance/journals/ymem/YMEM764Sfinalv2.pdf

16 Kumar A, Kasloff SB, Leung A, et al. Decontamination of N95 masks for re-use employing 7 widely available sterilization methods. PLoS One 2020;15:e0243965.

17 Doshi S, Banavar SP, Flaum E, et al. Applying heat and humidity using stove boiled water for decontamination of N95 respirators in low resource settings. medRxiv 2020.

18 Gawande A. Keeping the coronavirus from infecting healthcare workers. The New Yorker, 2020.

19 Kratzel A, Todt D, V'kovski P, et al. Inactivation of severe acute respiratory syndrome coronavirus 2 by WHO-Recommended hand rub formulations and alcohols. Emerg Infect Dis 2020;26:1592-5. 
20 Ruan Q, Yang K, Wang W, et al. Clinical predictors of mortality due to COVID-19 based on an analysis of data of 150 patients from Wuhan, China. Intensive Care Med 2020;46:846-8.

21 Tobin MJ. Basing respiratory management of COVID-19 on physiological principles. Am J Respir Crit Care Med 2020;201:1319-20.

22 Alhazzani W, Møller MH, Arabi YM, et al. Surviving sepsis campaign: guidelines on the management of critically ill adults with coronavirus disease 2019 (COVID-19). Intensive Care Med 2020;46:854-87.

23 Bouak F, Eaton D. Oxygen therapy. DRDC Toronto TM 2004;112.

24 Sjoding MW, Dickson RP, Iwashyna TJ, et al. Racial bias in pulse oximetry measurement. N Engl J Med 2020;383:2477-8.

25 National Institutes of Health. COVID-19 treatment guidelines. Available: https://covid19treatmentguidelines.nih.gov/ [Accessed 23 Apr 2020].

26 Caputo ND, Strayer RJ, Levitan R. Early Self-Proning in awake, Non-intubated patients in the emergency department: a single ED's experience during the COVID-19 pandemic. Acad Emerg Med 2020;27:375-8

27 Jagan N, Morrow LE, Walters RW, et al. The positioned study: prone positioning in Nonventilated coronavirus disease 2019 Patients-A retrospective analysis. Crit Care Explor 2020;2:e0229.

28 Padrão EMH, Valente FS, Besen BAMP, et al. Awake prone positioning in COVID-19 hypoxemic respiratory failure: exploratory findings in a single-center retrospective cohort study. Acad Emerg Med 2020;27:1249-59.

29 Awake prone positioning to reduce invasive ventilation in COVID-19 induced acute respiratory failurE. Available: https://ClinicalTrials.gov/ show/NCT04347941 [Accessed 26 Apr 2020].

30 CORONA (COvid pRONe hypoxemiA): Prone positioning for hypoxemic COVID-19 patients with Do-Not-Intubate goals (CORONA) - Identifier NCT04402879," ed: ClinicalTrials.gov, 2020.

31 Scholten EL, Beitler JR, Prisk GK, et al. Treatment of ARDS with prone positioning. Chest 2017;151:215-24.

32 Mehta P, McAuley DF, Brown M, et al. COVID-19: consider cytokine storm syndromes and immunosuppression. Lancet 2020;395:1033-4.

33 Russell CD, Millar JE, Baillie JK. Clinical evidence does not support corticosteroid treatment for 2019-nCoV lung injury. Lancet 2020;395:473-5.

34 Wu C, Chen X, Cai Y, et al. Risk factors associated with acute respiratory distress syndrome and death in patients with coronavirus disease 2019 pneumonia in Wuhan, China. JAMA Intern Med 2020;180:934-43.

35 RECOVERY Collaborative Group, Horby P, Lim WS, et al. Dexamethasone in hospitalized patients with Covid-19. N Engl J Med 2021;384:693-704

36 Zhou F, Yu T, Du R, et al. Clinical course and risk factors for mortality of adult inpatients with COVID-19 in Wuhan, China: a retrospective cohort study. Lancet 2020;395:1054-62.

37 Goyal P, Choi JJ, Pinheiro LC, et al. Clinical characteristics of Covid-19 in New York City. N Engl J Med 2020;382:2372-4.

38 Day M. Covid-19: ibuprofen should not be used for managing symptoms, say doctors and scientists. BMJ 2020;368:m1086.

39 Wang M, Cao R, Zhang L, et al. Remdesivir and chloroquine effectively inhibit the recently emerged novel coronavirus (2019nCoV) in vitro. Cell Res 2020;30:269-71.

40 Yao X, Ye F, Zhang M, et al. In vitro antiviral activity and projection of optimized dosing design of hydroxychloroquine for the treatment of severe acute respiratory syndrome coronavirus 2 (SARS-CoV-2). Clin Infect Dis 2020;71:732-9.

41 Tang W, Cao Z, Han M. Hydroxychloroquine in patients with COVID-19: an open-label, randomized, controlled trial. medRxiv 2020:2020.04.10.20060558.

42 Borba MGSet al. Chloroquine diphosphate in two different dosages as adjunctive therapy of hospitalized patients with severe respiratory syndrome in the context of coronavirus (SARS-CoV-2) infection: preliminary safety results of a randomized, doubleblinded, phase Ilb clinical trial (CloroCovid-19 study). medRxiv 2020:2020.04.07.20056424.

43 I. J. o. A. Agents. Statement on IJAA paper. Available: https://www. isac.world/news-and-publications/official-isac-statement [Accessed 17 Apr 2020].

44 Magagnoli J, Narendran S, Pereira F, et al. Outcomes of hydroxychloroquine usage in United States veterans hospitalized with Covid-19. medRxiv 2020. doi:10.1101/2020.04.16.20065920. [Epub ahead of print: 21 Apr 2020].

45 Self WH, Semler MW, Leither LM, et al. Effect of hydroxychloroquine on clinical status at 14 days in hospitalized patients with COVID-19: a randomized clinical trial. JAMA 2020;324:2165-76.

46 Bilaloglu S, Aphinyanaphongs $Y$, Jones S, et al. Thrombosis in hospitalized patients with COVID-19 in a New York City health system. JAMA 2020;324:799-801.

47 Tang N, Bai H, Chen X, et al. Anticoagulant treatment is associated with decreased mortality in severe coronavirus disease 2019 patients with coagulopathy. J Thromb Haemost 2020;18:1094-9.

48 Thachil J, Tang N, Gando S, et al. ISTH interim guidance on recognition and management of coagulopathy in COVID-19. J Thromb Haemost 2020;18:1023-6.

49 Hamid U, Krasnodembskaya A, Fitzgerald M, et al. Aspirin reduces lipopolysaccharide-induced pulmonary inflammation in human models of ARDS. Thorax 2017;72:971-80.

50 Matharu GS, Kunutsor SK, Judge A, et al. Clinical effectiveness and safety of aspirin for venous thromboembolism prophylaxis after total hip and knee replacement: a systematic review and meta-analysis of randomized clinical trials. JAMA Intern Med 2020;180:376-84.

51 Chow JH, Khanna AK, Kethireddy S, et al. Aspirin use is associated with decreased mechanical ventilation, intensive care unit admission, and in-hospital mortality in hospitalized patients with coronavirus disease 2019. Anesth Analg 2021;132:930-41.

52 Davidson BL, Verheijen S, Lensing AWA, et al. Bleeding risk of patients with acute venous thromboembolism taking nonsteroidal anti-inflammatory drugs or aspirin. JAMA Intern Med 2014;174:947-53.

53 Beigel JH, Tomashek KM, Dodd LE, et al. Remdesivir for the Treatment of Covid-19 - Final Report. N Engl J Med 2020;383:1813-26.

54 Hung IF-N, Lung K-C, Tso EY-K, et al. Triple combination of interferon beta-1b, lopinavir-ritonavir, and ribavirin in the treatment of patients admitted to hospital with COVID-19: an open-label, randomised, phase 2 trial. Lancet 2020;395:1695-704.

55 Anon. An EUA for Bamlanivimab-A monoclonal antibody for COVID-19. JAMA 2021;325:880-1.

56 FDA. Coronavirus (COVID-19) update: FDA authorizes monoclonal antibodies for treatment of COVID-19, 2020.

57 McGinley L. Only one COVID-19 treatment is designed to keep people out of the hospital. Many overburdened hospitals are not offering it. The Washington Post, 2020.

58 Simonovich VA, Burgos Pratx LD, Scibona P, et al. A randomized trial of convalescent plasma in Covid-19 severe pneumonia. $N$ Engl J Med 2021;384:619-29.

59 Agarwal A, Mukherjee A, Kumar G. Convalescent plasma in the management of moderate covid-19 in adults in India: open label phase II multicentre randomised controlled trial (PLACID trial). BMJ 2020;151:m3939.

60 Kemp SA, Collier DA, Datir R, et al. Neutralising antibodies in spike mediated SARS-CoV-2 adaptation. medRxiv 2020. doi:10.1101/2020 12.05.20241927. [Epub ahead of print: 29 Dec 2020].

61 Boseley S. Nine out of 10 in poor nations to miss out on inoculation as West buys up Covid vaccines. The Guardian, 2020. 